\title{
EXPECTATIVAS DOS ALUNOS DO PRIMEIRO SEMESTRE DOS CURSOS DE ENGENHARIA
}

\author{
EXPECTATIONS OF FIRST SEMESTER STUDENTS \\ IN ENGINEERING COURSES
}

\begin{abstract}
EXPECTATIVAS DE LOS ALUMNOS DEL PRIMER SEMESTRE DE LOS CURSOS DE INGENIERÍA
\end{abstract}

\author{
Breno Arno Hoernig JR \\ Universidade LaSalle (UNILASALLE/ Canoas) \\ Paulo Fossatti \\ Universidade La Salle (UNILASALLE/Canoas)
}

\begin{abstract}
Resumo $\mathrm{O}$ tema deste artigo está relacionado às expectativas apresentadas pelos alunos que iniciam a sua jornada acadêmica numa Instituição de Ensino Superior Comunitária (IESC), no sul do Brasil. Este estudo tem por objetivo identificar as expectativas dos alunos ingressantes nos diferentes cursos de Engenharia oferecidos por Instituição de Ensino Superior Comunitária (IESC). A metodologia adotada é do tipo qualitativa descritiva, pois se trata de um estudo de caso, onde participam do levantamento alunos das Engenharias. Foi feito um levantamento estatístico com os dados demográficos, a fim de caracterizar o grupo de interesse da pesquisa, usando o programa aplicado a Estatística - SPSS. A seguir, fez-se uma categorização das respostas associadas ao questionário aberto sobre suas expectativas, que foi aplicado aos alunos matriculados em uma disciplina de primeiro semestre. Os resultados apontam que os alunos têm expectativas voltadas à atividade profissional futura $\mathrm{e}$, principalmente, à qualidade em sua formação acadêmica, que se mostrou como sendo a expectativa de maior ênfase. Sepùlveda $(2013$, p. 1) chama a atenção de que tal situação ocorre também no contexto da educação superior no Chile, onde ele menciona tem-se "una generación ambiciosa que tiende a postergar el ingreso al mundo laboral y que reconoce en las credenciales educativas un requisito fundamental para su inserción en el mundo adulto". Conclui-se que as expectativas dos alunos, apesar de incertas e muitas vezes inconstantes, devem ser objeto de interesse da instituição, a fim de que, ao atender a essas expectativas estimule a permanência do aluno até a sua conclusão na graduação da Engenharia. Palavras-chave: Ensino Superior; Engenharia; Expectativas.
\end{abstract}


Abstract The theme of this article is related to the expectations presented by the students who begin their academic journey in a Community Higher Education Institution (CHEI), in southern Brazil. This study aims to identify the expectations of incoming students in the different Engineering courses offered by Community Higher Education Institution (CHEI). The methodology adopted is of the qualitative-descriptive type, since it is a case study, where students of Engineering participate in the survey. A statistical survey was done with the demographic data to characterize the research interest group, using the program applied to Statistics - SPSS. Next, a categorization of the answers associated with the open questionnaire about their expectations was done, which was applied to students enrolled in a first semester course. The results show that the students have expectations related to the following categories: labor market; formative quality; knowledge added to professional experience; personal fulfillment and professional training. It is concluded that the expectations of the students, although uncertain and often inconsistent, should be the object of interest of the institution, in order that, in meeting these expectations, it stimulates the student's permanence until his conclusion in the Engineering degree.

Key-words: Higher Education; Engineering; Initial Expectations.

Resumen El tema de este artículo está relacionado con las expectativas presentadas por los alumnos que comienzan su jornada académica en una Institución de Enseñanza Superior Comunitaria (IESC), al sur de Brasil. Este estudio tiene por objetivo identificar las expectativas de los alumnos ingresantes en los distintos cursos de Ingeniería ofrecidos por esa Institución de Enseñanza Superior Comunitaria (IESC). La metodología adoptada es del tipo cualitativa descriptiva, pues se trata de un estudio de caso, en el que participan alumnos de las Ingenierías. Fue hecho un levantamiento estadístico con los datos demográficos, con objeto de caracterizar al grupo de interés de la investigación, usando el programa aplicado a la Estadística - SPSS. A continuación, se hizo una categorización de las respuestas asociadas al cuestionario abierto sobre sus expectativas, que fue aplicado a los alumnos matriculados en una asignatura de primer semestre. Los resultados señalan que los alumnos tienen expectativas orientadas a la actividad profesional futura $\mathrm{y}$, principalmente, a la calidad de su formación académica, que se mostró la expectativa de mayor énfasis. Sepùlveda (2013, p. 1) llama la atención que dicha situación ocurre también en el contexto de la educación superior en Chile, donde él menciona hay una "una generación ambiciosa que tiende a postergar el ingreso al mundo laboral y que reconoce en las credenciales educativas un requisito fundamental para su inserción en el mundo adulto". Se concluye que las expectativas de los alumnos, a pesar de inciertas y muchas veces inconstantes, deben ser objeto de interés de la institución, a fin de que, al atender a esas expectativas, estimule la permanencia del alumno hasta su conclusión en el curso de Ingeniería.

Palabras-clave: Enseñanza Superior; Ingeniería; Expectativas. 


\section{INTRODUÇÃo}

Este artigo trata das expectativas que acompanham o aluno quando do seu ingresso nas Engenharias. Segundo Gomes e Soares (2013, p. 81), "expectativas são as predições que a pessoa faz em relação ao seu desempenho em um determinado contexto social para atender não só as suas necessidades como as dos outros".

Para Soares et al. (2014, p. 50), "as expectativas dos alunos tendem a influenciar a sua adaptação, persistência e sucesso acadêmico". Conforme Porto e Soares (2017, p. 14), que citam Igue, Bariani e Milaneses (2008), a expectativa do aluno é um dos fatores relevantes para a sua adaptação, integração e satisfação, influenciando diretamente sua permanência no Ensino Superior. Desse modo, torna-se relevante conhecer as expectativas dos alunos que devem ser objeto de interesse da instituição, a fim de atender a essas expectativas e estimular a permanência do aluno até que obtenha a conclusão de sua graduação.

Andrade (2016, p. 15) faz uma breve descrição das diversas categorias, em que se enquadram as Instituições de Ensino Superior no Brasil, a saber:

a) públicas: são as instituições sob a administração do Estado, ou seja, são mantidas pelo Poder Público Federal, Estadual ou Municipal. As instituições públicas devem manter gratuidade tanto de matrícula quanto de mensalidades, conforme Lei $n^{\circ}$. 9.394, de 20 de dezembro de 1996.

b) Privadas: são instituições criadas, mantidas e administradas por pessoas físicas ou jurídicas de direito privado e que possuem fins lucrativos (BRASIL, 1996).

c) Comunitárias (consideradas públicas não estatais): são organizações sem fins lucrativos (associações ou fundações) de direito privado, que possuem patrimônio pertencente à sociedade civil ou ao poder público, não distribuem sua renda $\mathrm{e}$ aplicam integralmente os recursos obtidos nas suas atividades, além de desenvolverem permanentemente ações sociais, conforme Lei $n^{\circ} .12 .881$, de 12 de novembro de 2013.

Segundo a autora, as instituições comunitárias apresentam como características a formação integral, compreendendo a preparação para a carreira profissional e a formação cidadã de seus alunos.

Este estudo de caso se deu em uma IESC, situada na Grande Porto Alegre/RS, onde são oferecidos diversos cursos de Engenharia com diferentes ênfases que buscam atender à demanda da região. Vale ressaltar que a transição do Ensino Médio para o Superior é reconhecida como um período de transição nos ideais e nas motivações dos alunos, em especial, aqueles que procuram pelas Engenharias. Segundo Porto e Soares (2017, p. 14), ancorados em diversos autores, consideram que "as expectativas e a adaptação acadêmica são construtos que se correlacionam e podem se refletir na permanência e no sucesso acadêmico". Jackson e colaboradores, citados por Nadelson et al. (2013, p. 52), afirmam que "a compreensão das expectativas dos calouros é essencial para prever as capacidades de adaptação desses alunos". 
Porém, verificando-se as informações fornecidas pelo Censo da Educação Superior/2015 no Brasil, a Engenharia tem se mostrado nos últimos anos com elevada taxa de evasão e apresentou um índice de permanência de $34,8 \%$ e de conclusão de apenas $8,7 \%$ em 2014. Conforme ilustra o Gráfico 1, a seguir.

\section{Gráfico 1 - Taxas de permanência, desistência e conclusão}

\section{Engenharias}

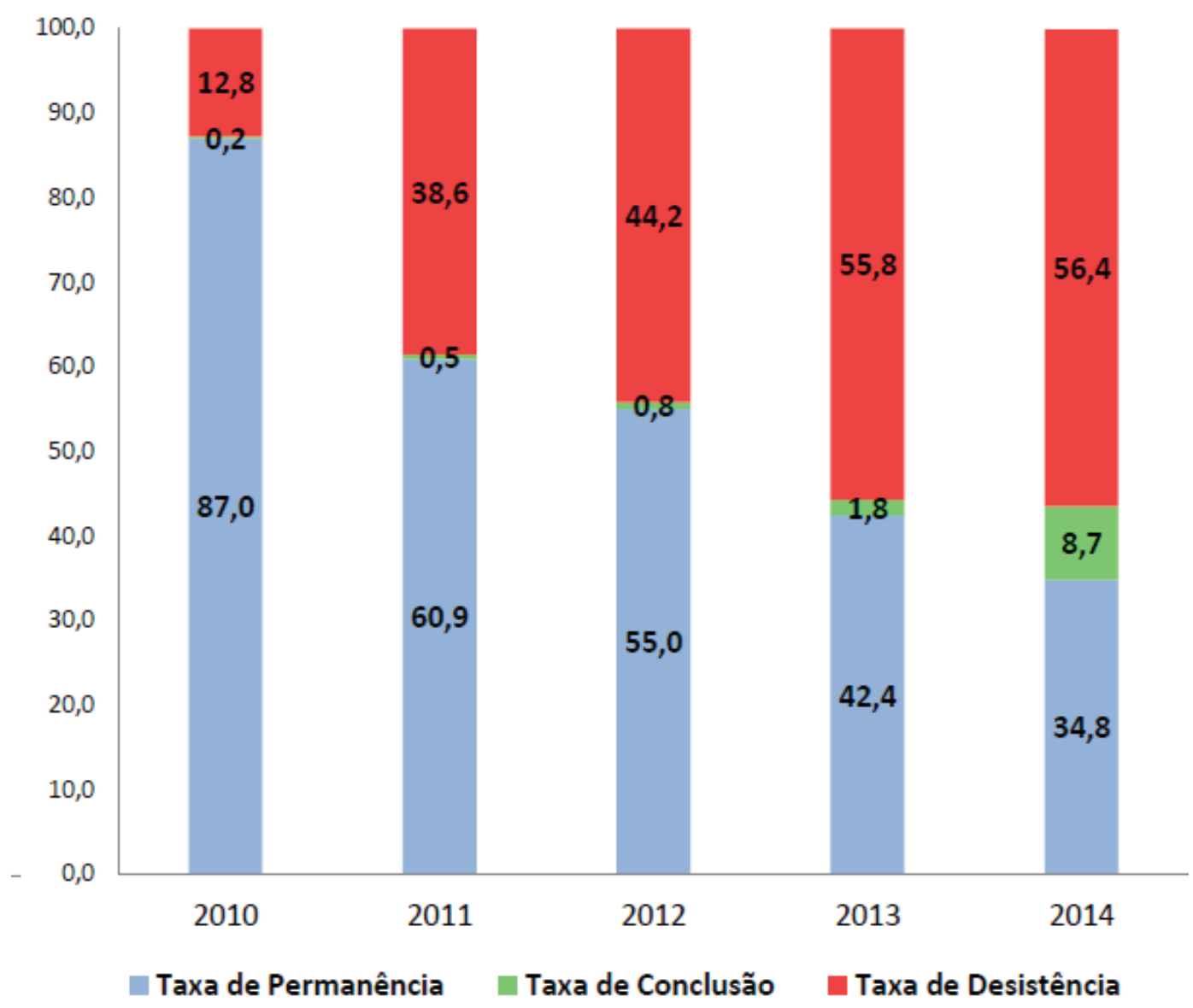

Fonte: Inep/Censo da Educação Superior/2015.

Portanto, tal pesquisa justifica-se pelo motivo imprescindível de identificar as expectativas dos alunos dessa graduação. Este estudo tem por objetivo identificar as expectativas dos alunos ingressantes nos diferentes cursos de Engenharia oferecidos por Instituição de Ensino Superior. 


\section{Metodologia}

A metodologia usada neste estudo tem caráter qualitativo-descritivo e utiliza um questionário de pesquisa que contempla questões de aspectos demográficos, uma questão aberta, aspectos relacionados à expectativa do aluno quanto ao curso em que está matriculado. Para tanto, se propôs a seguinte questão: Quais suas expectativas quanto ao seu curso de graduação nesta instituição de ensino?

O questionário foi aplicado para alunos da disciplina: Desenho Técnico (DT), de uma Instituição IESC, nas quais um dos autores deste artigo é docente dessa disciplina. Essa disciplina faz parte do plano de estudo dos cursos de Design Gráfico e de Arquitetura e Urbanismo e nas diversas modalidades de Engenharia, como Produção, Computação, Ambiental, Química, Mecânica e Elétrica. A disciplina tem carga horária de 60 h no semestre, sendo oferecidas no turno da noite às $2^{\text {as }}$. e $3^{\text {as }}$. feiras.

O questionário foi aplicado durante os 20 minutos iniciais da aula, no período chamado de pré-aula. O professor da disciplina foi quem aplicou o instrumento, que levou aproximadamente 15 minutos para ser respondido. As respostas ao questionário foram feitas em meio físico com devolução ao professor da disciplina que apresentou as questões no quadro da sala de aula. Não foi identificado o nome dos alunos respondentes, a fim de garantir o anonimato dos mesmos no corpus a ser analisado. A aplicação do questionário foi realizada independentemente do curso do aluno, posto que na referida disciplina encontramos alunos de diversos cursos. Para fins de análise, neste estudo foram usadas somente as respostas dos estudantes dos cursos de Engenharia.

O total de alunos de Engenharia matriculados na disciplina de DT foi de 30 e o total de respondentes 28 . A menor quantidade de respondentes em relação ao número de matriculados é devido ao fato de o questionário ter sido aplicado no período de pré-aula, sendo que nesse período a frequência não é obrigatória, e muitos alunos chegam à sala de aula após a pré-aula. Também houve falta de alunos no dia da aplicação do questionário e pelo fato de ser a primeira aula da disciplina no semestre que se iniciava em 2017.

\section{REVISÃo DE LITERATURA}

Sabe-se que o ingresso no Ensino Superior traz consigo expectativas e objetivos singulares para cada aluno. Segundo Araujo (2015, p. 202), um dos fatores que diferenciam os alunos na transição do Ensino Médio para o Ensino Superior são as suas expectativas acadêmicas, que condicionam o nível de envolvimento nas atividades dentro do contexto acadêmico.

Gomes e Soares (2013, p. 781) asseveram que a admissão na graduação provoca elevados níveis de expectativas relacionadas ao futuro e aos desafios que os alunos irão enfrentar. Tais autores afirmam que o aluno ingressante nesse novo contexto pode adequar suas expectativas ou enfrentar uma situação de frustração que dependerá dos recursos individual e/ou institucional, disponíveis para se ajustarem ao novo contexto educacional. 
Os autores já citados mencionam que diversos pesquisadores buscam entender o comportamento de certas variáveis que influenciam o desempenho do aluno. Entre elas, têm-se as expectativas acadêmicas. Para tais autores, as expectativas são as predições que a pessoa faz em relação ao seu desempenho, neste caso no contexto do ensino superior. Gomes e Soares (2013, p. 781) afirmam que: "as expectativas em relação ao ingresso à Universidade podem interferir na transição do aluno do Ensino Médio para o Ensino Superior o que significa dizer que, quanto maior o nível de expectativas existirem, maiores são as inferências dos estudantes geradas por estas".

Pela experiência no contexto de sala de aula, percebe-se que as expectativas são reflexos das motivações pessoais dos alunos, em realizar um curso de graduação no ensino superior. Também se constata que os alunos, em geral, apresentam expectativas otimistas e bastante elevadas por estarem frequentando tal nível de ensino.

Na perspectiva de Sepúlveda e Valdebenito (2014, p. 246-247) encontramos que:

En el ámbito de la investigación educativa existe un amplio consenso para reconocer que las aspiraciones que construyen los sujetos constituyen uno de los más importantes predictores de sus resultados educacionales y labores futuros. [...] Las expectativas remiten mayormente a los juicios de lo que probablemente ocurra dada la situación actual.

O fato de ter-se conhecimento das expectativas dos alunos é um fator fundamental para as propostas de melhorias, tanto em nível pedagógico/metodológico, por parte dos professores, quanto em ações da instituição, para que se possa fazer parcerias de fidelização do aluno junto a esta.

De acordo com Costa et al. (2013, p. 65), temos que:

As expetativas acadêmicas funcionam como um filtro, através do qual os estudantes avaliam e dão sentido à informação e vivência atuais, tendo em conta experiências passadas e perspectivando o futuro, permitindo aos alunos definirem os domínios aos quais devem aplicar o seu esforço e dedicação, e funcionando como um estímulo para o comportamento.

Muitas vezes, no ambiente de sala de aula, os alunos expressam suas expectativas em relação às questões acadêmicas com o curso e nas disciplinas em que estão matriculados, bem como, suas atitudes diante dos desafios das diferentes demandas a que devem atender continuamente no seu processo formativo.

Costa (2013, p. 65) afirma que as expectativas iniciais são relevantes para os alunos do primeiro ano e que elas, não sendo satisfeitas, influenciam negativamente no engajamento do processo educativo. Fritsch et al. $(2015$, p. 85) afirmam que "a não concretização das expectativas individuais dos alunos" é um dos fatores que corroboram na evasão do ensino superior. Por sua vez, Crisps et al. (2009, p. 13) reconhecem que a transição do ensino secundário para a universidade é um grande desafio para os estudantes, e que os alunos necessitam receber diferentes níveis de apoio da universidade, da família e dos pares, a fim de percorrerem um 
caminho bem-sucedido durante sua vida acadêmica. Esses autores mencionam que os alunos se matriculam nas diferentes graduações por motivos diferentes e seus argumentos para interromper seus estudos são complexos. Eles também asseveram que "a cultura universitária, e suas diferentes manifestações em nível das disciplinas, muitas vezes pode apresentar expectativas novas e confusas para a maioria dos estudantes do primeiro ano". ${ }^{1}$

Por sua vez, Tinto (2012, p. 11-12) afirma que muitos estudantes iniciam a educação superior sem conhecimento das expectativas, porém, ele diz ainda que é responsabilidade da instituição criar um clima para os seus alunos e grupos de pares que promova clara, consistente e elevadas expectativas. Segundo esse autor, a retenção estudantil é influenciada pelas expectativas que a instituição estabelece para a qualidade ou nível de empenho requerido de seus alunos.

Desse modo, ele observa que elevada expectativa é uma condição para o sucesso estudantil, baixa expectativa prescreve o insucesso. Para Tinto (2012, p. 14), altas expectativas resultam em alta performance e que pessoas com altas expectativas alcançam um nível mais elevado do que as com baixas expectativas, ainda que suas habilidades avaliadas sejam as mesmas.

Crips et al. (2009, p. 13) citam Kuh, Gonyea \& Williams (2005), que examinaram os fatores que influenciam as expectativas dos alunos e concluíram que os mais fortes eram cognitivos e psicológicos. Essas expectativas incluíram habilidades (notas esperadas), aspirações educacionais (possibilidades de grau mais elevado), motivação (horas esperadas para estudar) e uma atitude positiva preexistente para universidade (gostarem da instituição). As diferenças socioeconômicas representaram pouca variação nas expectativas, assim como o tipo de instituição atendida.

Para Tinto (2012, p. 10-11), as expectativas podem ter um forte efeito no desempenho do aluno, tanto quanto as expectativas que ele tem de si mesmo e aquelas que ele necessita alcançar. Ele afirma também que as expectativas estudantis são necessárias para o sucesso nas faculdades, pois elas são caracterizadas não somente pelo conhecimento apresentado pelo estudante anteriormente, conforme o ingresso, mas também pelo conteúdo acadêmico que ele toma posse a partir da faculdade, em especial do corpo docente. ${ }^{2}$

Gomes e Soares (2013, p. 782) citam Miller (2005), que menciona que entre as situações, os alunos dos primeiros anos da graduação poderão se deparar com expectativas distorcidas da realidade e fantasiosas. Com isso, tornam-se disfuncionais os objetivos traçados pelo próprio aluno. Olhando para essa perspectiva, Nadelson et al. (2013, p. 52) mencionam Smith e Wertlieb (2005), os quais relatam que as expectativas dos alunos não estavam alinhadas com suas experiências acadêmicas e sociais no primeiro ano, e que o desalinhamento é consistente com aspectos do "mito calouro", que incluíam expectativas irrealistas e não satisfeitas no primeiro ano do aluno.

1 University culture, and its disparate manifestations at the discipline level, often presents new and confusing expectations to the majority of first-year students (CRIPS et al., 2009, p. 13).

2 Student expectations as to what is needed to succeed in college are shaped not only by the prior knowledge students possess at entry but also by academic advice, they receive from faculty or staff. 
Por sua vez, Crips et al. (2009, p. 52) se basearam na pesquisa de Smith \& Wertlieb (2005), que compararam as expectativas sociais e acadêmicas dos estudantes do primeiro ano com suas experiências no meio e no fim de seu primeiro ano de faculdades nos EUA. Eles relataram um desalinhamento significativo entre as expectativas acadêmicas e sociais dos alunos e suas experiências de primeiro ano. Este estudo também constatou que os alunos com expectativas acadêmicas irrealistas tendem a ter notas inferiores no primeiro ano, em comparação com aqueles alunos com expectativas médias ou baixas de sua capacidade acadêmica.

Conforme Crips et al. (2009 p. 13), às vezes há uma diferença significativa entre as expectativas dos alunos e a experiência que as instituições estão dispostas a oferecer. Isso pode surgir porque os alunos têm expectativas irreais do que acontecerá durante seu tempo na universidade; também pode surgir por causa de mal-entendidos associados com as informações fornecidas pela instituição sobre sua cultura ou porque a instituição simplesmente desconhece as expectativas dos alunos. Segundo eles, os professores universitários podem fazer suposições erradas a respeito das necessidades dos alunos, já que as universidades tendem a fornecer informações aos alunos com base nas expectativas das instituições e não nas expectativas dos seus alunos.

Tinto (2012, p. 15) menciona que as instituições agem de várias maneiras para dar forma às suas expectativas. Primeiro, elas estabelecem expectativas claras e consistentes para o comportamento do aluno e os requisitos para a conclusão de grau ou obtenção do certificado. Em segundo lugar, elas ajudam os alunos a estabelecer expectativas para si próprios e lhes fornecem roteiros claros sobre o que é necessário para o sucesso em seus programas de estudo. Em terceiro lugar, trabalhando com o corpo docente, elas estabelecem expectativas claras e consistentes acerca do que é necessário para o sucesso na sala de aula.

Para Tinto (2012, p. 14), é responsabilidade da instituição criar um clima para os indivíduos e grupos de pares que promovam claras, consistentes e elevadas expectativas. Todavia, Nadelson et al. (2013, p. 50) mencionam que a falta de alinhamento pode ser um fator que contribui para as taxas de atrito entre os alunos e a instituição, provocando o uso ineficiente dos recursos disponibilizados pela instituição, e como consequência, a perda de oportunidade para promover crescimento e desenvolvimento formativo do aluno na instituição.

Nessa perspectiva, Araujo et al. $(2015$, p. 203) afirmam que o "desencontro entre expectativas iniciais e vivências posteriores aparece associado a dificuldades na integração acadêmica e social, bem como, à insatisfação, estresse e abandono do Ensino Superior". Por sua vez, a autora comenta que, quando ocorre de fato uma congruência entre expectativas do aluno e vivências, tal situação proporciona níveis mais elevados de motivação, persistência e sucesso.

Nadelson et al. (2013, p. 52) mencionam que os alunos do primeiro ano, provenientes de famílias que tiveram alguma experiência no Ensino Superior, tendem a ter expectativas diferentes daqueles alunos que são de primeira geração. Por sua vez, Tinto (2012, p. 11) afirma que os alunos da primeira geração na faculdade e estudantes de baixa renda, tipicamente carecem de ter um maior interesse pelo conhecimento ou no capital cultural. Estudantes mais ricos provenientes de uma educação de melhor qualidade, comum para famílias de posses, 
apresentam quase que uma natural experiência. e o que é necessário para obter o sucesso. Esse autor sugere que as instituições promovam atividades orientadas, como assessoria, programas no campus, e serviços de suporte estudantil, que podem ajudar o estudante de baixa renda e/ou de $1^{\text {a }}$. geração na graduação em sua trajetória acadêmica na instituição.

Cripps (2009, p. 14) propõe a seguinte questão: Por que as instituições devem cuidar das expectativas dos alunos?

Como resposta ele afirma, com base em Longden (2006), que as expectativas dos alunos e sua experiência durante o primeiro ano têm uma influência tangível no envolvimento e na retenção dos alunos. As instituições que estão interessadas em influenciar as taxas de retenção dos alunos precisam abordar a questão de forma prioritária. Tinto (2012, p. 17) afirma:

If pre-entry expectations are very different from experience following entry ("this is not what I expected"), students may decide to leave. But is enrollment management helps students form initial expectations that are consistent whit experience following entry, its actions can promote retention. ${ }^{3}$

Considerando que as expectativas dos alunos em relação às suas experiências na universidade são variadas, quando esses são solicitados a compartilhar suas razões para frequentar uma faculdade ou expressar suas expectativas quanto ao futuro, muitas das respostas incluem obtenção de mais recursos financeiros, de mais conhecimento e melhores oportunidades na profissão com abertura de novas possibilidades para o mercado. Wyer (2005), citado por Nadelson et al. (2013), afirma que "especificamente, o desejo dos alunos de adquirir maior riqueza é um fator que tem mostrado aumento significativo nos últimos 30 anos.

Friedman e Mandel (2009, p. 229) mencionam duas teorias usadas extensivamente na literatura de pesquisa em negócios que têm o potencial de fornecer insights sobre retenção de estudantes. Estes são a teoria da expectativa e a teoria de definição de metas. Segundo eles, a teoria da expectativa da motivação afirma que a motivação é uma função da probabilidade percebida de que o esforço resultará no desempenho que determinará os resultados e que esses resultados serão avaliados.

Eles comentam que a probabilidade percebida pelo indivíduo, de que o esforço que resultará em seu desempenho é uma função, em parte, de experiências passadas em situações semelhantes. Assim, em situações anteriores, em que o esforço do indivíduo o levou a obter resultados satisfatórios, pode aumentar a probabilidade das expectativas em tarefas semelhantes no futuro. Por sua vez, as falhas passadas, em que o esforço do indivíduo o levou a um mau desempenho, podem reduzir a expectativa. Para Friedman e Mandel (2009, p. 230), as experiências escolares são uma mistura de diversas influências e os níveis de esforço dos alunos são variáveis. Por exemplo, os alunos cujos professores são competentes e respondem às suas necessidades de aprendizagem podem aumentar a crença de que, se realizarem esforços, obterão boas notas.

3 Se as expectativas pré-entrada são muito diferentes da experiência após a entrada ("isto não é o que eu esperava"), os alunos podem decidir sair. Mas o gerenciamento de inscrições ajuda os alunos a formar expectativas iniciais que são consistentes com a experiência após a entrada, suas ações podem promover a retenção. 
Segundo esses autores, os alunos que não receberam recompensas pelo bom desempenho podem ter baixa expectativa e, portanto, podem ter menor motivação do que os alunos cujos desempenhos anteriores foram recompensados. Eles também mencionam que alguns alunos podem preferir boas notas em relação ao estabelecimento de redes sociais, fazer amigos e participar de organizações estudantis. Eles também citam MsShane e Von Glinow (2005), os quais afirmam que os indivíduos que estabelecem metas são mais propensos a se comportar em níveis mais elevados do que os indivíduos que não estabelecem metas. $\mathrm{O}$ estabelecimento de metas é mais complexo do que simplesmente dizer aos alunos para fazer o seu melhor. McShane \& Von Glinow (2005) demonstraram em suas pesquisas que estabelecer metas desafiadoras e participar do processo de definição de metas influencia positivamente o desempenho.

Para Friedman e Mandel (2009, p. 230, 231), os objetivos que são mensuráveis e que podem ser acompanhados ao longo do tempo comunicam expectativas de desempenho mais específico. Segundo esses autores, os alunos que estabelecem metas mensuráveis podem ser capazes de concentrar seus esforços de forma mais eficiente do que os alunos que definem objetivos vagos ou que não têm objetivos. Os alunos que estabelecem metas específicas relevantes para a vida do estudante e sob seu controle são mais propensos a ser motivados para atender à expectativa de desempenho estabelecida no objetivo.

Tais autores citam Urdan e Mestas (2006), os quais afirmam que a competição entre pares pode também ser um elemento importante do desempenho e da retenção dos alunos. Nesse sentido, a competição entre pares é definida como o desejo dos alunos de fazer melhor do que outros ou evitar fazer pior do que outros. Esses autores verificaram que $40 \%$ dos alunos afirmaram terem perseguido seus objetivos de desempenho acadêmico por causa da concorrência de pares. Tais autores sugerem o emprego das teorias da expectativa e da definição de metas para prever a motivação do aluno, o seu desempenho acadêmico, e que elas sejam utilizadas como parâmetros para a retenção dos alunos na graduação.

Outro enfoque importante no contexto educacional é a sala de aula, onde ela é o ambiente-chave no processo formativo dos alunos, e nesse sentido Tinto $(2012$, p. 12) afirma:

Nowhere are expectations more important than in classroom. Success there pro-
vides the foundation for student retention and graduation. Classroom expecta-
tions are shaped less by advice than by a student's interaction with teachers and,
to some degree, whit fellow students. ${ }^{4}$

Estepp e Roberts (2013, p. 180) mencionam que, quando a sala de aula é um ambiente acolhedor (hospitaleiro), permite que se estabeleça a construção de relações interpessoais que geram um aumento significativo da motivação dos alunos e eleva o nível de seu en-

4 Em lugar algum, essas expectativas são mais importantes do que na sala de aula. Sucesso nesse lugar promove a base de retenção dos alunos até sua graduação. Expectativas na sala de aula são menos constituídas de palpites e opiniões, e sim pela interação do estudante com os professores, monitores e com os demais colegas. (Tradução do autor.) 
volvimento no processo formativo propostos pela instituição. Nesse sentido, Quadros et al. (2010, p. 102) expressam que:

\begin{abstract}
A sala de aula é um espaço de formação humana, de vivência e convivência e de relações pedagógicas que se destinam ao crescimento individual dos sujeitos na interação como outro e com o conhecimento. É um espaço constituído pela diversidade e heterogeneidade de ideias, valores e crenças.
\end{abstract}

No contexto de sala de aula, um dos pesquisadores que ministram a disciplina de Desenho Técnico enfatiza que o ambiente é apropriado para que se estabeleçam relações entre os alunos e destes com o professor. Tais interações se dão nas realizações de atividades pedagógicas e na formação de vínculos. O mesmo se verifica na sala de informática com o uso de programas específicos de expressão gráfica.

Para Quadros et al. (2010, p. 104), sendo a sala de aula um espaço no qual diferentes sujeitos compartilham aprendizagens, por meio de relações que se constroem por intermédio das diversas interações entre professor e aluno e entre os alunos entre si, pode-se ter um ambiente conflituoso, sobretudo no que se refere às expectativas dos envolvidos nesse ambiente singular de formação e aprendizagem. Partindo da afirmação feita por Quadros et al. (2010, p. 114), onde os autores concluem que: "trabalhar nesse universo de "diferentes" certamente é um desafio para os professores, e o gerenciamento da sala de aula é uma tarefa que precisa ser mais bem entendida tanto nas instituições de Educação Básica quanto nas de Ensino Superior".

Nessa perspectiva, Gurgel et al. (2012, p. 181) mencionam que é necessário considerar que os alunos são indivíduos diversificados com relação às suas experiências pessoais, aos conhecimentos adquiridos e às expectativas sobre o que e como aprender. Por encontrar nesse ambiente distintos alunos, Pires $(2013$, p. 10,11) apresenta, ancorado em Jacson e colaboradores (2000), quatro grupos de estudantes que podem estar presentes nas salas de aula de qualquer instituição, a saber: a) os "otimistas", aqueles alunos que têm expectativas muito positivas e, por vezes irrealistas, sobre a vida acadêmica na universidade; b) os "preparados", aqueles alunos com expectativas positivas dosadas com certa consciência das dificuldades e exigências que terá pela frente; c) os "receosos", aqueles alunos com fracas expectativas em função do elevado nível de receio e de apreensão quanto ao que lhes aguarda no futuro próximo; d) os "complacentes", aqueles alunos com pequenas expectativas e com uma fraca postura diante das exigências da graduação.

Nota-se que tais características são observadas nos alunos quanto ao aspecto da expressão de suas expectativas. Somam-se, ainda, traços de personalidade de cada indivíduo, bem como, seus temperamentos e motivações no contexto de uma sala de aula, o que torna um lugar singular no processo de ensino-aprendizagem.

Com frequência se verifica que as expectativas dos estudantes que ingressam na graduação são frustradas, principalmente nos primeiros meses da graduação e, por conseguinte, gera-se um acréscimo expressivo no índice de evasão dos diversos cursos oferecidos pelas Universidades. Tal fato é marcante nos cursos de Engenharia, onde o Censo da Educação Su- 
perior/2015 indicou uma taxa alarmante de desistência na ordem de 56,4\%, conforme ilustra o Gráfico 1. Assim sendo, é fundamental que se conheçam as expectativas desses alunos para que se tenha noção de suas aspirações e objetivos ao escolher essa instituição de ensino.

\section{DisCUSSÃo dos RESULTAdoS}

\section{Dados Sociodemográficos}

De posse do questionário respondido pelos alunos dos diversos cursos matriculados na disciplina, realizou-se uma primeira triagem, separando os alunos da engenharia, foco deste estudo. A seguir, fez-se um levantamento para identificar os cursos de engenharia que responderam à questão proposta. Posteriormente, forneceram-se os dados para o programa SPSS para uma análise descritiva. A Tabela 1 apresenta o número de alunos da engenharia matriculados em DT que participaram da enquete e os respectivos cursos de Engenharia.

Tabela 1 - Curso de Graduação nas Engenharias.

\begin{tabular}{lr|r|r|r} 
& Frequência & Porcentagem & $\begin{array}{l}\text { Porcentagem } \\
\text { válida }\end{array}$ & \multicolumn{2}{|c}{$\begin{array}{l}\text { Porcentagem } \\
\text { acumulativa }\end{array}$} \\
\hline Eng. de Produção & 4 & 14,3 & 14,3 & 14,3 \\
\hline Eng. Ambiental & 2 & 7,1 & 7,1 & 21,4 \\
\hline Eng. Química & 9 & 32,1 & 32,1 & 53,6 \\
\hline Eng. Mecânica & 6 & 21,4 & 21,4 & 75,0 \\
\hline $\begin{array}{l}\text { Eng. de } \\
\text { Computação }\end{array}$ & 7 & 25,0 & 25,0 & 100,0 \\
\hline Total & 28 & 100,0 & 100,0 & \\
\hline
\end{tabular}

Fonte: Os autores, 2017.

A partir da identificação das idades dos respondentes, foi elaborada a distribuição de frequência, adotando-se intervalos de mesma amplitude, conforme mostra a Tabela 2.

Tabela 2 - Idades dos alunos em intervalos de classe.

\begin{tabular}{|c|c|c|c|c|c|}
\hline & & Frequência & Porcentagem & $\begin{array}{l}\text { Porcentagem } \\
\text { válida }\end{array}$ & $\begin{array}{c}\text { Porcentagem } \\
\text { acumulativa }\end{array}$ \\
\hline \multirow{6}{*}{ Idades: } & de 16 anos até 20 anos & 10 & 35,7 & 35,7 & 35,7 \\
\hline & de 21 anos até 25 anos & 6 & 21,4 & 21,4 & 57,1 \\
\hline & de 26 anos até 30 anos & 4 & 14,3 & 14,3 & 71,4 \\
\hline & de 31 anos até 35 anos & 5 & 17,9 & 17,9 & 89,3 \\
\hline & de 36 anos até 40 anos & 3 & 10,7 & 10,7 & 100,0 \\
\hline & Total & 28 & 100,0 & 100,0 & \\
\hline
\end{tabular}

Fonte: Dados dos autores. 
Por intermédio dos dados, verifica-se que os alunos mais jovens, de 16 até 20 anos de idade, são em maior quantidade e a seguir vêm adultos jovens na faixa de 21 até 25 anos. A partir dos dados coletados, observou-se que o aluno(a) de menor idade tem 16 anos e que o aluno(a) de mais idade 40 anos, o que determina entre eles uma diferença de 24 anos. Obteve-se que a média foi de 24,86 anos, a mediana 22,50 e a idade modal foi de 17 anos.

A seguir, fez-se o levantamento quanto ao gênero, conforme a Tabela 3.

Tabela 3 - Gênero dos alunos.

\begin{tabular}{lcc|c}
\hline & & Frequência & Porcentagem \\
\hline \multirow{3}{*}{ Sexo: } & Masculino & 18 & 64,3 \\
\cline { 2 - 4 } & Feminino & 10 & 35,7 \\
\cline { 2 - 4 } & Total & 28 & 100,0 \\
\hline
\end{tabular}

Fonte: Os autores, 2017.

Nota-se que o sexo masculino predomina nas Engenharias, que corresponde a 64,3\%, enquanto que o sexo feminino representa $35,7 \%$ desse total.

Uma vez identificado o gênero, fez-se uma estratificação por curso, conforme mostra a Tabela cruzada 3 .

Tabela cruzada 3 - Gênero e Curso de Graduação.

\begin{tabular}{ccc|c|c|c|c|c} 
& & $\begin{array}{c}\text { Eng. de } \\
\text { Produção }\end{array}$ & $\begin{array}{c}\text { Eng. } \\
\text { Ambiental }\end{array}$ & $\begin{array}{c}\text { Eng. } \\
\text { Química }\end{array}$ & $\begin{array}{c}\text { Eng. } \\
\text { Mecânica }\end{array}$ & $\begin{array}{c}\text { Eng. de } \\
\text { Computação }\end{array}$ & \\
\hline \multirow{2}{*}{ Gênero } & Masculino & 2 & 2 & 2 & 6 & 6 & 18 \\
\cline { 2 - 9 } & Feminino & 2 & 0 & 7 & 0 & 1 & 10 \\
\hline & Total & 4 & 2 & 9 & 6 & 7 & 28 \\
\hline
\end{tabular}

Fonte: Os autores, 2017.

A tabela cruzada 3 mostra que na disciplina de DT desse semestre os cursos de Engenharia Mecânica e Ambiental são representados por apenas alunos do gênero masculino, enquanto o curso da Engenharia da Computação mostra um predomínio dos alunos do gênero masculino, o inverso do que se dá no curso de Engenharia Química, que apresenta predominância do gênero feminino.

Araujo et al. (2015, p. 203) mencionam que existe certa distinção nas expectativas acadêmicas relacionadas ao gênero dos alunos. Segundo os autores, as alunas apresentam expectativas mais elevadas de envolvimento acadêmico e de relacionamento interpessoal e com uma taxa de conclusão superior nas diferentes graduações. Por sua vez, afirmam que os alunos apresentam expectativas mais elevadas em relação ao investimento no curso, como oportunidade de acesso ao emprego ou a uma carreira profissional. O que foi evidenciado pela resposta dada por alunos de Engenharia Mecânica e de Produção, que apontam para as expectativas voltadas ao mercado. 
A seguir, fez-se um levantamento das idades dos alunos e a vinculação com os respectivos cursos de engenharia, conforme mostra a Tabela cruzada 4.

Tabela cruzada 4 - Idades em classes nos Cursos de Engenharia.

\begin{tabular}{|c|c|c|c|c|c|c|c|}
\hline & & $\begin{array}{c}\text { Eng. } \\
\text { Produção }\end{array}$ & $\begin{array}{c}\text { Eng. } \\
\text { Ambiental }\end{array}$ & $\begin{array}{c}\text { Eng. } \\
\text { Química }\end{array}$ & $\begin{array}{c}\text { Eng. } \\
\text { Mecânica }\end{array}$ & $\begin{array}{c}\text { Eng. } \\
\text { Computação }\end{array}$ & \\
\hline \multirow{2}{*}{ dades } & De 16 anos até 20 anos & 0 & 0 & 5 & 2 & 3 & 10 \\
\hline & De 21 anos até 25 anos & 2 & 1 & 2 & 0 & 1 & 6 \\
\hline $\mathrm{m}$ & De 26 anos até 30 anos & 0 & 0 & 0 & 2 & 2 & 4 \\
\hline \multirow{2}{*}{ lasses } & De 31 anos até 35 anos & 1 & 1 & 1 & 1 & 1 & 5 \\
\hline & De 36 anos até 40 anos & 1 & 0 & 1 & 1 & 0 & 3 \\
\hline & Total & 4 & 2 & 9 & 6 & 7 & 28 \\
\hline
\end{tabular}

Fonte: Os autores, 2017.

A tabela identifica que na Engenharia Química preponderam alunos jovens, na faixa de 16 até 20 anos de idade, inclusive, e que os cursos de Engenharia de Produção e Ambiental não apresentam alunos matriculados em DT nessa faixa etária. Os cursos de Engenharia Ambiental de Computação não apresentam alunos com idade igual ou superior a 36 anos.

\section{LEVANTAMENTO DE CATEGORIAS}

Posteriormente, passou-se à unitarização ${ }^{5}$ e à categorização $0^{6}$ inicial (pré-categorias) das respostas obtidas nesta enquete.

1. Crescimento pessoal e realização profissional: 2A22EQ (7) -3A10EQ (15)-3A22(27)--------------- $\sum$ = 3

2. Oportunidade no mercado de trabalho: A6EP (12) - 3A8EP (14) - 3A21EM (26)--------------------- $\sum=3$

3. Conhecimentos adequados para o futuro: 2A5EA(2) - 2A6EC(3) - 3A4EQ(10) - 3A7EM(13)

- 3A12EM(17) - 3A13EC(18) - 3A2EP(25)----------------

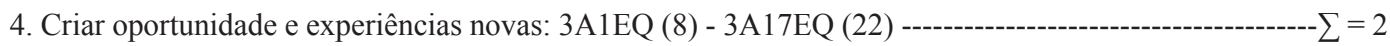

5. Almejar objetivos pessoais: 2A3EC (1) - 3A11EQ (16) ---------------------------------------- $\sum$ = 2

6. Conteúdos satisfatório e compatível para o exercício profissional: $2 \mathrm{~A} 7 \mathrm{EC}(4)$ - 2A16EP(6)

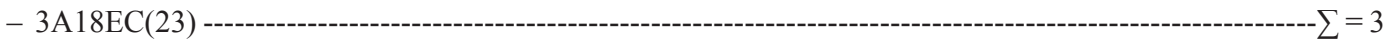

7. Aprimorar conhecimentos e agregar com experiência profissional: 2A13EM(5) -

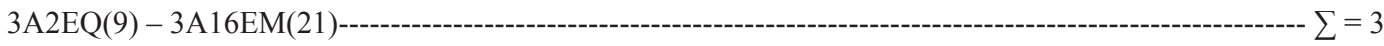

8. Não ser o curso desejado: 3A14EM (19) ----on

9. Identificação com o curso: 3A5EA (11) - 3A19EC (24) - 3A23EQ (28)------ $\sum=3$

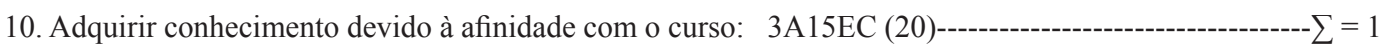

5 Unitarização é o processo de desmontagem dos textos, implica examinar os textos em detalhes, fragmentando-os no sentido de atingir unidades constituintes referentes aos fenômenos estudados (MORAES e GALIAZZI, 2007, p. 11).

6 Categorização envolve construir relações entre as unidades de base, combinando-se e as classificando, reunindo esses elementos unitários na formação de conjuntos que agregam elementos próximos (MORAIS E GALIAZZI, 2007, p. 12). 
Feita essa categorização inicial (pré-categorização), passou-se posteriormente à sua análise e a uma fase de agrupar em categorias mais abrangentes, da seguinte forma: Associadas ao mercado de trabalho - 2 e 4; Qualidade formativa - 3 e 6;

Conhecimento agregado à experiência profissional -1 e 7 ;

Realização pessoal e capacitação profissional $-5,8,9$.

Estabelecidas as categorizações, foram elaboradas a quantificação de cada uma delas, conforme mostra a Tabela cruzada 5.

Tabela Cruzada 5 - CATEGORIAS e Alunos Respondentes.

\begin{tabular}{lc|c}
\hline & Frequência & Porcentagem \\
\hline Associada ao mercado de trabalho & 5 & 17,9 \\
\hline Qualidade formativa & 11 & 39,3 \\
\hline Conhecimento agregado à experiência profissional & 6 & 21,4 \\
\hline Realização pessoal e capacitação profissional & 6 & 21,4 \\
\hline Total & 28 & 100,0 \\
\hline
\end{tabular}

Fonte: Os autores, 2017.

Pela Tabela 5, que identifica as categorias e as quantidades de respostas associadas às mesmas, verificou-se que a categoria II - qualidade formativa se mostra com maior ênfase nesta pesquisa, enquanto as demais se apresentam com uma distribuição mais homogênea. Porto e Soares (2017, p. 14) consideram que as expectativas em relação ao curso podem ser distintas, mas citam que envolvem pelo menos dois aspectos: realização pessoal e a sustentabilidade financeira.

Nesse sentido, as categorias I e IV se enquadram nessa perspectiva. Conforme as afirmações dos alunos relativas à categoria I - Expectativas associadas ao mercado de trabalho, encontramos:

"Curso que me desenvolva pessoal e profissionalmente e que me deixe preparado para enfrentar novos desafios no mercado de trabalho" (3A6 - Eng. de Produção).

"Espero obter a preparação necessária de acordo com as exigências mais atuais do mercado de trabalho no ramo da computação" (3A18 - Eng. da Computação).

"O curso de Engenharia Mecânica é um curso que sempre quis fazer e também uma ótima oportunidade de trabalho" (3A21 - Eng. Mecânica).

Nesse aspecto, se percebe que os alunos manifestam expectativas de ingresso no mercado, tendo por base que os diferentes cursos os capacitem de forma adequada e que os alunos tenham as habilidades e as competências para a demanda que eles deverão atender. Dentro desse contexto, existem aqueles alunos que já estão atuando e que demonstraram as expectativas relativas à categoria III - Expectativas relacionadas com o conhecimento agregado à experiência profissional, e temos as seguintes colocações:

"Por trabalhar numa siderúrgica e com a expectativa de crescimento dentro da empresa decidi fazer a Engenharia Mecânica" (3A16 - Eng. Mecânica). 
"O curso de Engenharia Mecânica era o que eu queria, pois trabalho há anos em metalurgia e preciso de curso para melhorar as oportunidades do mercado de trabalho" (2A13 - Eng. Mecânica).

"Aprimorar conhecimentos na área na qual já atuo com efetivo ensino e reconhecimento" (3A2 - Eng. Química).

Nessa categoria, nota-se que aluno que está imerso no ambiente de trabalho espera adquirir conhecimentos adequados aos diferentes contextos. Destaca-se, nessa categoria, ser possível estabelecer relações entre a sua experiência no campo de trabalho com o conhecimento de caráter acadêmico. Quanto ao aspecto da realização como indivíduo como caracteriza a categoria IV - Expectativas de realização pessoal e capacitação profissional, encontramos os seguintes dizeres:

"Encanta-me realizar meus planejamentos de vida acadêmica e para o futuro. E fazer aquilo de que eu gosto de fazer, no caso, de ficar em um laboratório fazendo vários experimentos" (3A10 - Eng. Química).

"Cada semestre que passa tenho mais certeza que escolhi o curso certo. Espero que continue gostando cada vez mais" (3A1 - Eng. de Computação).

"Espero ser um curso onde me identifique e possa seguir uma carreira de sucesso" (3A23 - Eng. Química).

Nessa categoria, encontramos alguns alunos com expectativas voltadas à sua realização de ordem pessoal e de interesse individual. Nota-se que esses alunos almejam aprimorar suas habilidades a fim de alcançar seus objetivos profissionais. Soares et al. (2014, p. 3) citam a pesquisa realizada por Casanova e Polydoro (2009), onde esses autores ressaltam a importância de os professores explicitarem a atualidade e a relevância dos conteúdos oferecidos para os alunos da graduação.

Nesse sentido, para a categoria II - Expectativas dos alunos quanto à qualidade formativa que os cursos oferecem, temos as seguintes colocações:

"Pretendo ao longo do curso aprimorar meus conhecimentos na área de mecânica e aprender algo novo a cada aula que passa" (3A7 - Eng. Mecânica).

"Espero que o curso de Engenharia de produção me forneça toda a base necessária e todo conhecimento sobre essa área, para que assim eu possa desempenhar minhas atividades com máxima eficiência em minha empresa" (3A20 - Eng. de Produção).

"Conhecer de forma ampla os diversos campos de atuação de um engenheiro químico, obtendo uma completa realização profissional quando escolher o campo de minha preferência, tornando-me um profissional capacitado, confiável e completo" (2A22 - Eng. Química).

"Espero aprender mais sobre uma área que já me fascina há muito tempo" (3A15 Eng. de Computação).

Nessa categoria, alguns alunos demonstram expectativas associadas à apropriação de conhecimento e a desenvolver capacidades que o tornem competente para a futura atividade profissional escolhida por ele. Pode-se dizer que essas diferentes categorias obtidas são formas de como o aluno percebe e se prepara para um futuro próximo, e como se posiciona para a sua atuação profissional.

Comunicações | Piracicaba | v. 25 | n. 3 | p. 163-183| set.-dez. 2018 
Pelos resultados obtidos, nota-se que os alunos do $1^{\circ}$. semestre apresentam uma expectativa acentuada quanto à qualidade formativa de suas graduações para o posterior ingresso no mercado. Os alunos declaram que depositam um elevado grau de confiança e credibilidade na instituição e nos cursos de engenharia que esta lhes proporciona.

Constata-se que uma parcela dos alunos apresenta expectativas associadas à sua realização pessoal e capacitação profissional, enquanto os alunos que já estão no mercado de trabalho têm expectativas relativas a adquirirem conhecimentos adequados e propícios à atividade que exercem. Segundo Hoernig e Fossatti (2017, p. 9), "as demandas da sociedade atual necessitam de pessoas capazes de desenvolverem cientifica e tecnologicamente interagindo com um meio altamente exigente". Nesse sentido, alguns alunos associam suas expectativas às oportunidades de acesso ao mercado de trabalho, devido ao ingresso nos cursos de graduação que lhes proporcionam uma capacitação adequada no exercício da engenharia.

\section{CONSIDERAÇões FINAIS}

Percebemos nas respostas dos alunos matriculados nas graduações de Engenharia diferentes aspectos relacionados às expectativas que eles trazem consigo. As respostas apresentadas são pertinentes a situações futuras, como as de ingresso no mercado de trabalho e, também estão associadas ao presente da sala de aula, em especial a de formação do conhecimento técnico que essas graduações exigem. Nota-se que alguns teóricos explicitam que pode ocorrer certa divergência entre as expectativas dos alunos e as da instituição, o que acarretaria um aumento na taxa de evasão de tais cursos.

O grupo de interesse desta pesquisa foi constituído em grande parte de alunos jovens com anseios e objetivos que se refletem nas expectativas positivas quanto à formação a ser obtida nos cursos de Engenharia em suas diferentes modalidades. Nesse sentido, a categorização das expectativas fez que se identificasse que esta é a principal perspectiva para esses alunos no primeiro semestre. Esse fato torna-se fator a ser explorado pelos agentes promotores do processo educativo dessa instituição.

Reconhece-se como limitação desta pesquisa o tamanho da amostra considerada, fato que impossibilita a generalização dos resultados. Porém, esta pesquisa pode fornecer subsídios para ações de adequação e aprimoramento nas diferentes estratégias elencadas numa instituição de Ensino Superior. Tal estudo com esses resultados poderá contribuir para outras pesquisas a serem realizadas e oferecer sinais claros para a melhoria dos processos educativos de modo que permitam um aumento no índice de permanência do aluno no Ensino Superior e principalmente de que ele venha completar sua formação com êxito nas Engenharias. 


\section{REFERÊNCIAS}

ANDRADE, Fádua Ionara Andrade de. Uma proposta de responsabilidade social universitária: aproximação entre SINAES, literatura e Unilasalle. Canoas, 2016, 114p. Dissertação (Mestrado em Educação). Centro Universitário La Salle, UNILASALLE, 2017.

ARAUJO, Alexandra M. et al. Variáveis pessoais e socioculturais de diferenciação das expectativas académicas: Estudo com alunos do Ensino Superior do Norte de Portugal e Galiza. Rev. Port. de Educação [on-line], v. 28, n. 1, p. 201-220, 2015. Disponível em: $<$ http://www.scielo.mec.pt/scielo.php?pid=S0871-91872015000100009\&script=sci arttext\&tlng=en>. Acesso em: 6 mar. 2017.

BRASIL. Censo da Educação Superior. Brasília: INEP/MEC, 2015. Disponível em: $<$ http://download.inep.gov.br/educacao_superior/censo_superior/apresentacao/2015/Apresentacao_Censo_Superior_2015.pdf >. Acesso em: 7 out. 2016.

BRASIL. Lei $\mathbf{n}^{\mathbf{0}} \mathbf{. 9 . 3 9 4}$, de 20 de dezembro de 1996. Estabelece as diretrizes e bases da educação nacional. Brasília: INEP/MEC, 1996. Disponível em: http://www.planalto.gov. br/ccivil_03/leis/L9394.htm. Acesso em: 12 jul. 2015.

BRASIL. Lei $\mathbf{n}^{\mathbf{0}} \mathbf{. 1 2 . 8 8 1}$, de 12 de novembro de 2013. Dispõe sobre a definição, qualificação, prerrogativas e finalidades das Instituições Comunitárias de Educação Superior - ICES. Disponível em: $<\mathrm{http}$ ://www.planalto.gov.br/ ccivil_03/_Ato2011-2014/2013/Lei/L12881.htm>. Acesso em: 12 abr. 2015.

COSTA, Alexandra Ribeiro, et al. Expectativas académicas em alunos tradicionais e não-tradicionais de engenharia. Revista de Peruana de Psicología y Trabajo Social, v. 2, n. 1, p. 63-74, 2014. Disponível em:

$<$ https://revistaepsi.com/wp-content/uploads/artigos/2014/Ano4-Volume1-Artigo8.pdf $>$. Acesso em: 12 fev. 2017.

CRESWELL, John W. Projeto de pesquisa métodos qualitativo, quantitativo e misto. In: Projeto de pesquisa métodos qualitativo, quantitativo e misto. Artmed, 2010.

CRISP, Geoffrey, et al. First year student expectations: Results from a university-wide student survey. Journal of University Teaching and Learning Practice, v. 6, n. 1, p. 11-26, 2009. Disponível em: < http://files.eric.ed.gov/fulltext/EJ867293.pdf>. Acesso em: 17 mar. 2017.

ESTEPP, Christopher M.; ROBERTS, T. Grady. Exploring the relationship between professor/student rapport and students' expectancy for success and values/goals. In college of agriculture classrooms. Journal of Agricultural Education, v. 54, n. 4, p. 180-194, 2013. Disponível em: <http://www.jae-online.org/attachments/article/1793/jae54.4.pdf\#page=182>. Acesso em: 27 mar. 2017. 
FRIEDMAN, Barry A.; MANDEL, Rhonda G. The prediction of college student academic performance and retention: Application of expectancy and goal setting theories. Journal of college student retention: Research, theory \& practice, v. 11, n. 2, p. 227-246, 2009. Disponível em: <http://journals.sagepub.com/doi/pdf/10.2190/CS.11.2.d>. Acesso em: 25 abr. 2017.

FRITSCH, Rosangela; DA ROCHA, Cleonice Silveira; VITELLI, Ricardo Ferreira. A evasão nos cursos de graduação em uma instituição de ensino superior privada. Revista Educação em Questão, 2015, 52.38: 81-108. Disponível em: <https://periodicos.ufrn.br/ educacaoemquestao/article/view/7963>. Acesso em: 11 out. 2016.

GOMES, Gil; SOARES, Adriana Benevides. Inteligência, habilidades sociais e expectativas acadêmicas no desempenho de estudantes universitários. Psicologia: Reflexão e Crítica, v. 26, n. 4, p. 780-789, 2013. Disponível em: <https:/www.researchgate.net/profile/Adriana Benevides_Soares/publication/262442242_Intelligence_social_skills_and_academic_expectations_in_university_students'_performance/links/57c7fd5c08aec24de0438a77.pdf $>$. Acesso em: 23 nov. 2016.

GUERREIRO-CASANOVA, Daniela; POLYDORO, Soely. Integração ao ensino superior: relações ao longo do primeiro ano de graduação. Psicologia Ensino \& Formação, v. 1, n. 2, p. 85-96, 2010. Disponível em: <http://pepsic.bvsalud.org/scielo.php?script=sci_arttext \&pid=S2177-20612010000200008>. Acesso em: 12 ago. 2016.

GURGEL, Ludmila Galindo França, et al. Perfil dos discentes ingressos do Centro de Ciências da Saúde UFPE. Rev Bras Educ Med, v. 36, n. 2, p. 180-187, 2012. Disponível em: <https://www.researchgate.net/profile/Renata_Guimaraes/publication/262465966 Profile_of_enrolled_students_at_the_Center_for_Health_Sciences_at_UFPE/ links/540deb900cf2d8daaacd3755.pdf>. Acesso em: 12 abr. 2017.

HOERNIG, A. M.; FOSSATTI, P. A educação superior lassalista e as finalidades da educação superior. Gestão Universitária, v. 7, p. 1-19, 2017.

IGUE, Érica Aparecida; BARIANI, Isabel Cristina Dib; MILANESI, Pedro Vitor Barnabé. Vivência acadêmica e expectativas de universitários ingressantes e concluintes. PsicoUSF, v. 13, n. 2, p. 155-164, 2008. Disponível em: <http://pepsic.bvsalud.org/scielo. php?script=sci_arttext\&pid=S1413 82712008000200003>. Acesso em: 21 mar. 2017.

JACKSON, L. M.; PANCER, S. M.; PRATT, M. W. Great expectations: The relation between expectancies and adjustment during the transition to university. Journal of Applied Social Psychology, v. 30, n. 10, p. 2.100-2.025, 2000. Disponível em: <http://onlinelibrary. wiley.com/doi/10.1111/j.1559-1816.2000.tb02427.x/full>. Acesso em: 10 jan. 2017.

KUH, G. D., GONYEA, R. M.; WILLIAMS, J. M. What students expect from college and what they get. In: T. E. Miller, B. E. Bender, J. H. Schuh \& Associates (Org.). Promoting Reasonable Expectations: Aligning student and institutional views of the college experience. San Francisco, CA: Jossey Bass, 2005. 
LONGDEN, Bernard. An institutional response to changing student expectations and their impact on retention rates. Journal of Higher Education Policy and Management, v. 28, n. 2, p. 173-187, 2006.

MCSHANE, S. L.; VON GLINOW, M. A. Organizational behavior: Emerging realities for the workplace revolution. Boston, MA: Ed. McGraw-Hill Irwin, 2005.

MORAES, Roque; DO CARMO GALIAZZI, Maria. Análise textual: discursiva. Editora Unijuí, 2007.

NADELSON, Louis S., et al. Why Did They Come Here? - The Influences and Expectations of First-Year Students' College Experience. Higher Education Studies, v. 3, n. 1, p. 50, 2013. Disponível em: http://scholarworks.boisestate.edu/cgi/viewcontent. cgi article $=1144 \&$ context $=$ cifs_facpubs $>$.

Acesso em: 11 fev. 2017.

PIRES, Paula Graça Pereira. O afecto na adaptação dos estudantes do primeiro ano do Ensino Superior e seus correlatos. Diss. 2013.68s. Dissertação (Mestrado) - Mestrado em Psicologia do Trabalho e das Organizações, Universidade Fernando Pessoa, Porto, 2013. Disponível em: <http://bdigital.ufp.pt/handle/10284/5432>. Acesso em: 4 abr. 2017.

PORTO, Ana Maria da Silva; SOARES, Adriana Benevides. Diferenças entre expectativas e adaptação acadêmica de universitário de diversas áreas do conhecimento. Aná.Psicológica [on-line], v. 35, n. 1, p. 13-24, 2017. Disponível em: <http://www.scielo.mec.pt/scielo. php?pid=S0870-82312017000100002\&script=sci_arttext\&tlng=en $>$. Acesso em: 11 abr. 2017.

QUADROS, AL de et al. A percepção de professores e estudantes sobre a sala de aula de ensino superior: expectativas e construção de relações no curso de química da UFMG. Ciência e Educação, v. 16, n. 1, p. 103-114, 2010. Disponível em: <http://www.scielo.br/pdf/ ciedu/v16n1/v16n1a06>. Acesso em: 7 nov. 2016.

SEPÚLVEDA, Leandro. Más jóvenes en la educación superior, ¿ mayores esperanzas de igualdad social?: una reflexión sobre las aspiraciones de futuro de los estudiantes secundarios chilenos, 2013. Disponível em: <http://mailing.uahurtado.cl/cuaderno_educacion_51/pdf/articulo_1_LS_51_ok.pdf>. Acesso em: 4 mai. 2017.

SEPÚLVEDA, Leandro; VALDEBENITO, María José. ¿ Las cosas claras? Aspiraciones de futuro y proyecto educativo laboral de jóvenes estudiantes secundarios. Estudios pedagógicos (Valdivia), v. 40, n. 1, p. 243-261, 2014. Disponível em: < http://www.scielo.cl/pdf/ estped/v40n1/art15.pdf $>$ Acesso em: 7 abr. 2017.

SMITH, Joshua S.; WERTLIEB, Ellen C. Do first-year college students' expectations align with their first-year experiences? NASPA Journal, v. 42, n. 2, p. 153-174, 2005. Disponível em: <https://pdfs.semanticscholar.org/affc/249830f9b3c494a102539c1bd823ff224ffa. pdf $>$. Acesso em: 13 jan. 2017. 
SOARES, Adriana Benevides, et al. O impacto das expectativas na adaptação acadêmica dos estudantes no Ensino Superior. Psico-USF, v. 19, n. 1, p. 49-60, 2014. Disponível em: $<$ http://repositorium.sdum.uminho.pt/handle/1822/29263>. Acesso em: 14 mar. 2017.

TINTO, Vincent. Completing College. Rethinking Institution Action. Chicago, USA: Ed. UChicago Press, 2012.

\section{MINICURRÍCULO DOS AUTORES:}

\section{Breno Arno Hoernig Jr.}

Doutorando em Educação pela Universidade La Salle. Mestrado Engenharia na área de Energia. Pós-graduação em Gerenciamento Ambiental. Graduação em Engenharia Mecânica e em Esquema I - Formação de Professor - Disciplinas: Produção Mecânica, Desenho Técnico e Mecânica. Atualmente é professor nos cursos de Engenharia na Universidade La Salle. Integrante do grupo de pesquisa Gestão Educacional nos Diferentes Contextos da Universidade La Salle de Canoas.

\section{Paulo Fossatti}

Doutor em Educação, Pós-Doutorado em Ciências da Educação e pesquisador associado da Universidade do Algarve (2011). Graduação em Filosofia e em Psicologia. Especialista em Administração Escolar e mestrado em Psicologia Social e Institucional. Líder do Grupo de Pesquisa: Gestão Educacional nos diferentes contextos. Presidente da Associação Nacional da Educação Católica (ANEC), no Brasil. Reitor da Universidade La Salle Brasil, e pesquisador e docente do Programa stricto sensu de Pós-graduação em Educação dessa universidade.

Submetido em: 15-5-2017

Aceito em: $23-8-2018$ 